\title{
Caring Behaviors as Perceived by Emergency Nurses in Tunisia
}

\author{
Rihab Salhi ${ }^{* 1} \quad$ Hatem Shili $^{2}$ Chokri Hammouda ${ }^{3} \quad$ Anis Boujemaa $^{4}$ \\ 1. Licensed on emergency and resuscitation in Charles Nicolle Hospital - Master degree in sciences of health \\ from High school of health's sciences of Sousse (2014-2016)- Paramedical Professor \\ 2.Psychiatric Nurse- DEA (Diploma of Advenced) in Sociology- PPM (Paramedical Professor) - Hight Institut \\ Of Nursing Sciences \\ 3.Pr. In emergency and resuscitation medicine \\ 4.Engineer of statistics in National Institute of Statistics
}

\begin{abstract}
Patients are dissatisfied due to lack of human and relational aspects in care (Donabedian, 1992 cited in Rafii, 2008). Moreover, caregivers confirmed in a report published in 2013, that the quality of care in emergencies is poor (the Centre for Development of Best Practices in Health, 2013). To resolve this issue, Watson suggested applying treatments based on the Caring in this type of care despite its specific structure (Watson, 2010).Indeed, it would be important to measure the behavior of Caring nursing and emergency nurses from their perceptions. The focus of our research is to improve the quality of care in our emergency departments and consequently the patient satisfaction. The aim of this study is to describe perceptions of Caring for Emergency Nurses at University Hospitals of Greater Tunis and its relationship to socio-demographic characteristics. This is a correlational descriptive study, which was guided by the theory of "Human Caring" of Watson. To measure Caring behavior, the Caring behavior inventory (CBI) developed by Wolf, Giardino, Osborne and Ambrose (1994) was used. It is a questionnaire based on the caratifs factors of Watson's theory (Green, A, 2004). The study included all nurses who were trained in "License applied in Nursing" and working in the Emergency Departments of the university hospitals of Tunis (Charles Nicolle, Rabta, Mongi Slim and Habib Thameur). This survey showed that knowledge and professional skills belonged to the dimension that had the highest perception $(\mathrm{m}=1.06+/-0.37)$. Tunisians nurses were according more importance to the technical dimension and a less importance for relational dimensions. There is no relationship between the socio-demographic characteristics and the five dimensions of the CBI questionnaire. The results of this study did uncover a reality that has to undergo a serious change to improve the quality of care in Tunisia. Further studies are needed in order to improve quality of care and consequently patient satisfaction.
\end{abstract}

Keywords: Caring Behavior-Nurse-emergency-perception

DOI: $10.7176 / \mathrm{JHMN} / 69-03$

Publication date: December $31^{\text {st }} 2019$

\section{Introduction}

Patient's satisfaction remains a major challenge. Nurses are often asked to provide quality care to their patients. This fact has become more demanding. For us today, the concept of quality care is a vital issue. We cannot afford to settle into a routine practice centered on performing care tasks.

To develop the quality of care, it would be useful to organize care activities around a holistic approach to care for individuals, families and communities, focusing on their health needs by integrating relational dimension.

Although several studies have attached importance to the integration of relational and human dimension in nursing practice. Nurses are still loyal to an approach centered on the rather technical dimension (Karol,2008) (Bassett,2002) (Mirel et al,2012) (Arosa et al,2013). This trend gave more importance to technical care at the expense of the relational dimension. This reality can be explained by multiple constraints.

The evolution through the history of medical techniques and complexity of medical technology that has transformed the care and care giver credits in real strenuous technical experts to the medicalization in their interventions and let abandon much of the essence their true activity of care (Bucco,2015). Moreover, this phenomenon was intensified by the orientation at the training of nurses to acquire the technical skills, sometimes on the account of relationship skills. Brennier (2012), Azimzadeh (2013) and Bucco (2015) point out that this situation needs to undergo a radical change by giving more interest to the moral dimension of care that has become a requirement in all treatment units including emergencies (Bucco,2015) (Brenier, 2012) (Azimzadeh et al,2013).

The emergency department, like all departments, has its specificities. This is one of the units that saw a large flow rate and hence the consultations of patients are of short duration (Kimble,2003) (Muntlin,2006). The urgency receives several reasons for consultation as cardiac arrest, trauma and burns that represent the daily routine for nurses (Moerman,1996). Despite these challenges, nurses should consider the psychological part of the patient when making care into the framework of a holistic approach (Wiman et al,2003). Care is one of the concepts that constitute the essence of the nursing discipline (Pépin et al,2010). By observing the theories in nursing, there is a large place reserved for the relational and moral dimension of care (Theories de soin). This is the space in which 
the care givers will practice their art, as M-F. Collière describes. It is a responsibility of the nurse to their patients (Brown,2011).

Exercise and care practice is not strictly limited to practice nursing as a profession, but it includes a set of ethical and moral values of order such as compassion and dedication. Indeed, the care in the broadest sense is the act which allows preserving and ensuring the continuity of human life. The meaning of care is not simply attached to the presence of the disease. But on the contrary, recourse it concerns every day care (Collière,2001).

To have a good patient satisfaction, we must practice the person-centered care. Patient must beat the center of nursing practice (Kutney-Lee et al,2009). To achieve this result, nurse should adopt a care based on Caring because it represents the essence of care (Dingman,1999) (Rafii et al,2007). Satisfaction is too closely linked to Caring. Indeed, the Caring helps clinicians to establish a relationship with the patient, to release their powers of psychological, emotional and human care (Rafii et al,2007). By Caring, the nurse can access the inside of the patient's soul and help to overcome the difficult moments of their life and increase their chances of healing (Green, 2001).

In Tunisia, despite the transition in the formation of vocational training to university education, the exercise of the nursing profession remains an activity that lack of recognition of its autonomy. Nursing practice remains committed to the implementation of the medical prescription or acts delegated by the physicians. Even clinical learning provided by trainers pays more interest in learning technical skills of care to students.

Studies concerned with the extent Caring behavior perspective of nurses and /or patients in Tunisia are rare. Patients, in Tunisia, who consult emergency departments, always express their dissatisfaction of benefits received in that service. However, Chetoui and Parart (2002) emphasized that patients consulting emergency department of Kebili have a good assessment of the quality of service (Chetoui et al,2002).

In this context comes our work, by focusing on the Caring behavior of emergency nurses. It is important to measure the behavior of Caring. Indeed, it helps to understand the meaning that nurses give to their practices in Caring and it facilitates the orientation of research about this theme (2). It is this sense that will guide and direct the nurse's behavior in nursing care with patient (Essen,1991) (Dyess et al,2010). It also facilitates the orientation of research in this theme and to improve the quality of care in Tunisians hospitals. This improvement helps in resolving problems experienced with emergencies and increase patient satisfaction (Bassett,2002) (Bucco,2015).

\section{Study's purpose}

Tunisian context requires a change and improved quality of care and also the relationship between nurse and patient specifically in emergency services. In this context comes our study, which aims to describe the perception of emergency nurses at its own caring behaviors and its relationship with the socio-demographic characteristics of the participants.

\section{Methods}

This survey was a descriptive correlation study. It tried to look for the relationship between socio-demographic characteristics of the participants and their Caring behaviors of perception. Indeed, all nurses who have the inclusion criteria participated in this study. Finally, sixty-five nurses have accepted and signed consent forms $(\mathrm{N}=65)$. Data collection was performed through the CBI (Caring Behavior Inventory). The inventory of caring behaviors (CBI) was completed by nursing teams in the morning, afternoon and night at all emergency for hospitals: Charles Nicolle, Rabta, Mongi Slim and Habib Thameur. The data were analyzed using SPSS Version 19.0. 


\section{Results}

Table 1: Table: Socio-demographic characteristics of nurses

\begin{tabular}{|l|c|c|}
\hline Characteristics & N & \% \\
\hline Gender & 35 & 5.3 \\
\hline Men & 24 & 40.7 \\
Nomen & 06 & 10.0 \\
\hline Total & 65 & 100 \\
\hline Age & 34 & 57.6 \\
24-26 years & 22 & 37.3 \\
27-30 years & 03 & 05.1 \\
More than 30 years & 06 & 1 \\
NR & 65 & 100 \\
\hline Total & & 50.8 \\
\hline Professional experience & 30 & 28.8 \\
\hline 1 year & 17 & 20.3 \\
2 years & 12 & 10.0 \\
More than 2 years & 06 & 100 \\
NR & 65 & \\
\hline Total & & \\
\hline NR: non respond & 34 & \\
\hline
\end{tabular}

The results of the different dimensions of CBI that follow were calculated based on a scoring whose values are between -2 as minimum and +2 value maximum values. The scoring follows the distribution of levels Likert scale establishes four levels from, absolutely disagree that the value -2 until full agreement is set to +2

The graphic billow contains the average over each of the dimensions of CBI. Statistical analysis of the results can distinguish different turn of perceptions either positively or negatively with respect to a range between -0.5 and +0.5 we considered it as a neutral zone.

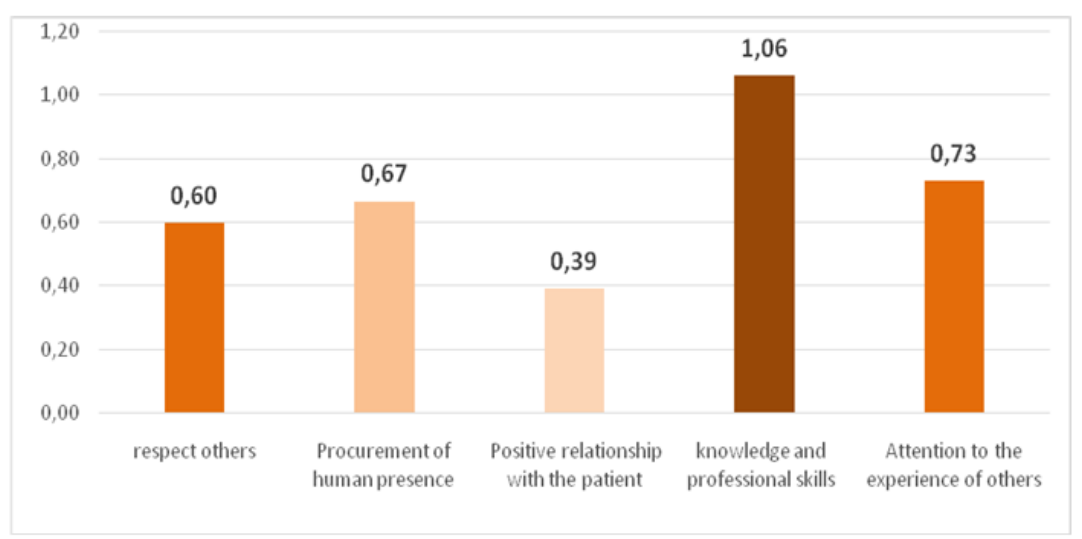

Figure 1: Mean of score of the five dimensions of CBI

The figure above shows that all dimensions have combined averages of the scores of positive perceptions of between $(\mathrm{m}=0.39+/-0.39$ and $\mathrm{m}=0.73+/-0.42)$, and we note that the dimension "knowledge and professional skills" has accumulated the highest score with $(\mathrm{m}=1.06+/-0.37)$. Indeed, the mean of the scores of the five dimensions $(\mathrm{M}=0.69+/-0.24)$ which is estimated to be slightly positive.

We didn't find a significant relationship between the socio-demographic characteristic of nurses who participated at this survey (age, gender and professional experience) and the five dimensions of the questionnaire. In fact, although the fifth dimension had the highest mean score, no significant difference was observed: $p$ value according to ANOVA test was $>0.05$.

\section{Discussion}

Our study is a descriptive correlational survey that aims to describe the perceptions of emergency nurses about their Caring behavior and its relationship with socio-demographic characteristics of respondents.

Throughout the discussion of the results of our study, we use the study Bruntan and Beaman (2000) and the study of Green (2004) that used the same questionnaire (CBI) but with a six levels of Likert scale ranging from 1 to 6 , while our Likert scale is limited to four levels with a minimum equal to -2 and a maximum +2 .

Indeed, in the study of Bruntan and Beaman (2000), nurses have given more importance to the relational dimensions: respect for the patient and ensure a human presence. However, in this study, these dimensions were 
lower compared to the technical dimensions: "the positive relationship with the patient", " professional knowledge and skills "and "the attention paid to the experiences of others ".

For the study of Green (2004); the perception of nurses was high for all dimensions of CBI. And as the study of Bruntan and Beaman (2000), relational dimensions had the highest perception " respect for others" with $(\mathrm{m}=$ $5.48)$, " the assurance of human presence " of an average $(\mathrm{m}=5.48)$, " positive relationship for the patient" $(\mathrm{m}=$ $5.16)$, " professional knowledge and skills " $(\mathrm{m}=5.39)$ and "attention facing the experience of others " has accumulated an average $(\mathrm{m}=5.46)$. In the light of the results of this study, we plan treat the discussion of each dimension separately.

5.1 The dimension "respect for others": includes 12 items

We were able to identify the care givers surveyed over all were a good perception of the order of $\mathrm{m}=0.60(+/-$ 0.44). Ten items of this size had a good perception. While the two items "spending time with the patient" and "address the patient by the name they prefer" are rather low with average equal to respectively $(\mathrm{m}=0.00)$ and $(\mathrm{m}$ $=-0.33+/-0.11)$

These last two items which are of low average appear to be explained by the nature of the terrain of the investigation which is the emergency room where the caregivers undertake a fairly heavy work load and the transitional passage of patients in most cases they return home, they are transferred and referral to other services. However, in the study of Bruntan and Beaman (2000) and the Green (2004), this dimension "respect for others" got the highest perception of nurses respectively, or $(\mathrm{m}=67.28)$ and $(\mathrm{m}=5.64)$.

In fact, it is essential to respect the person and to share with them health's experience. The behavior of caring adds value to the person through their progression and to find harmony between the different spheres mind-body - soul in Watson's perspective that considers the individual an inseparable whole in the quest for coherence between selfperceived and self-lived.

5.2. "Knowledge and professional skills ": Dimension includes 5 items

We noticed that the participants had a good perception about their knowledge and professional skills. The perception was of average $(\mathrm{m}=1.06+/-0.38)$. Besides, this is the dimension that has the better perception by respondent's nurses. This can be justified by the strong involvement of nurses in the technical dimension of care and a "know-how" developed with enough mastery of the techniques of care. But, Bruntan and Beaman (2000) found for the dimension 'knowledge and professional skills "has accumulated an average $(\mathrm{m}=25.71)$ and the study of Green (2004) the average is equal to $(\mathrm{m}=5.39)$ (Green,2001) (Brunton,2000). He asked the nurse to have a good command of the acts and care techniques but is not limited to purely in the tasks to be assigned or required.

\subsection{Dimension "positive relationship with the patient ": Includes 9 items}

On this dimension, respondents had a good overall perception of caring behavior with a score $(\mathrm{m}=0.39+/-0.39)$. Although the perception of care givers for some items was negative, as the item" use touch to communicate Caring" $(\mathrm{m}=-0.11+/-0.03)$ and the item "have empathy for the patient" $(\mathrm{m}=-0.08+/-0.02)$.

However, in the same study Bruntan and Beaman (2000), this dimension had a good sense of order $(\mathrm{m}=$ 46.12). In the study by Green (2004), this dimension received the lowest perception with $(\mathrm{m}=5.16)$. Behavior of caring helps the patient overcome their health's experience and to reach its inner strengths to transform their anxiety state of negative energy into positive energy for its progress and so the disease becomes an experience of life such as health.

\subsection{Dimension" the assurance of human presence":}

As for this dimension, nurses had a good perception for all 12 items with a mean of $(\mathrm{m}=0.67+/-0.26)$. Bruntan and Beaman (2000) also found that nurses attributed a high perception for this dimension $(\mathrm{m}=58.8)$ and $(\mathrm{m}=5.48)$ in the study of Green (2004).

Even at the level of emergency care units, nurses must successfully establish a reassuring human presence. In particular, deal with critical situations, patients presenting to emergency departments need to be listen, reassure and relieve their pain of their suffering. This is why nurses should integrate into their practices the caring behavior.

\subsection{The dimension "attention to the experience of others"}

This dimension includes 4 items. The perception of the nurses caring behavior was good with $(\mathrm{m}=0.73+/-0.42)$. In the item "bring attention to patients when it comes to a first hospitalization" had the lowest average for this dimension with $(\mathrm{m}=0.11+/-0.03)$.

Two items that had the highest averages are "Providing good care" $(\mathrm{m}=1.05+/-0.36)$ and "Give priority to the patient" ( $\mathrm{m}=0.91+/-0.32)$. On the contrary, to the work of Bruntan and Beaman $(2000)$, "attention facing the experience of others" had the lowest perception $(m=15.75)$. Green $(2004)$ found that nurses have a good perception for this dimension $(\mathrm{m}=5.46)$. 
As a result, this dimension is in the moment of the realization of care at the bedside (client) which nurses are required to deliver both physical quality care that morality to relieve symptoms of the disease while taking into consideration the meaning that gives the patient information about their illness.

According to the desired results, we consider that there is a difference between our results and those of the study of Green (2004) and Bruntan and Beaman (2000). Indeed, the dimensions that are at the top in this work are not the same as in other studies.

As a result, these results reflect that nurses participating in our survey do not have the same vision and the same conception of care developed by the nursing that participated in other studies. This difference can be explained for different reasons. The basis and level of training of nurse's relational dimension of care is hidden. Often the concept of care is directed at everything that is the technicality in the practice of care. Technical care takes priority in learning the nurses at the expense of relationships. While caring theorist, Jean Watson insists that "human caring" is the essence of the care that is based on understanding, empathy and human warmth to develop an empathetic attitude among caregivers.

In addition, during the course of our investigation and during data collection, participants have said they were not trained to practice Caring. Most nurses have found a difficulty remembering the Caring Theory of Watson. They also said that during their training course, the Caring was submitted only in the course of introduction to Nursing is presented as a theoretical course. Learning practice does not develop the skills of caring among future caregivers. Moreover, nurses newly recruited in hospitals doesn't guided by any order or organization which make the integration of theoretical knowledge, as Caring theory, in practice very difficult (Shili et al,2018).

This reality says the results found by Murphy (2009), which announced that the training of nurses cannot develop Caring behaviors get used to practicing care with a holistic approach according to the design of Jean Watson (Murphy,2009). The same study found that the perception of nursing students in their Caring behaviors fell between those of the first year level and those of the third year level (Murphy,2009).

So it is important to change the orientation of nursing training institutes to training that aims to teach students how can we establish a relationship in which both phenomenal fields of health care and patient meet. Training that allows the nurse to succeed in making a decision in holistic and transpersonal load with the patient. It should also work on changing the vision of caregivers to the concept of care and training to practice Caring design in their daily work to improve the satisfaction of emergency patients. Indeed, experimental research study of St-Pièrre (2008) showed that the nursing training is able to improve their behaviors Caring (Brunton,2000).

\subsection{The relationship between socio-demographic characteristics of the participants and Their Behaviors Caring: ANOVA Test:}

Although there is a difference between the two samples of this study and the study of Green (2004), there is no statistically significant relationship between socio-demographic characteristics and the perception of the participants. However, in the study of Bruntan and Beaman (2000), there was a significant difference between age and nurses' perception of their behavior Caring.

\section{Study's limitations:}

This work has two main limitations. The first is about sampling because most of the participants do not have much experience in emergency unit and the sample is small. The second relates to the survey instrument. Since CBI is validated in English but not in its French version. The version with which this study was conducted is a translated version and used in other works and whose Cornbach alpha equals to 0.7 .

\section{Conclusion}

The results of this study did uncover a reality that has to undergo a serious change to improve the quality of care in Tunisia. How nurse are trained is also responsible for this situation. It's time to shake up and correct the concept of care among Tunisian nurses and training to change attitudes and practices.

Further studies are needed to improve service quality and consequently patient satisfaction. A new teaching strategy is needed. Train nurses able to work and practice Caring as an art becomes an emergency in Tunisia. And to do so require the early months of the formation of the student, explain the importance of discipline and Caring in Nursing.

We must also change the mindset and vision those students regarding the concept of care. Using the theory of Watson, Tunisian nurses can make a revolution in the quality of care in emergencies. For this reason, a serious commitment is required. In addition, we must continue carrying out research to track the desired change.

\section{References}

1. Krol,P. Legault,A.(2008).Mieux comprendre l'apprentissage du Caring une nécessité pour préserver l'approche humaniste au cœur des soins, L'infirmière clinicienne.5- 1.

2. Bassett,C.(2002).Nurses' perceptions of care and caring.International Journal of Nursing Practice.8-15.

3. Mirrel,A. Hayes,J.Clukey,L.Curtis,D.(2012). Do they Really Care? How Trauma Patients Perceive Nurses' 
Caring Behaviors.Journal of trauma nursing.19-1.

4. Airosa,F.Halkenberg,T.Ohlén,G.Arman,M.(2013).Tactile massage or healing touch: Caring touch for patients in emergency care - A qualitative study.European Journal of Integrative Medicine.374-381.

5. Bucco,T.(2015).The Relationships Between Patients' Perceptions of Nurse Caring Behaviors, Nurses' Perceptions of Nurse Caring Behaviors and Patient Satisfaction in the Emergency Department. Seton Hall University Dissertations and Theses.194.

6. Brenier,C.(2012).Les émotions du soignant [dissertation].IFSI Niort .39 p.

7. Azimzadeh,R.Valizadeh,L.Zamanzadeh,V.Rahmani,A.(2013).What are important for patient centered care? A quantitative study based on perception of patients' with cancer. Journal of Caring Sciences.321-327.

8. Kimble,L.(2003).Patients' Perceptions of Nurse Caring Behaviors in M.S.an Emergency Department. Marshall University.46.

9. Muntlin,A.Gunningberg,L.Carlsson,M.(2006).Patients perceptions of quality of care at an emergency department and identification of areas for quality improvement.Journal of Clinical Nursing.1045-1056.

10. Moerman,M.(1996).Caring Behaviors in the Emergency Department: Perceptions of Patients and Nurses. [Master's thesis], Grand Valley State University. 71p.

11. Wiman,A.Wikblad,K.(2003).Caring and uncaring encounters in nursing in an emergency department. Journal of Clinical Nursing.422-429.

12. Pépin,J.Kérouac,S and Ducharme F.(2010).La pensée infirmière : conceptions et stratégies, $3^{\text {nd }}$ ed. Canada : Chenelière éducation.206 p.

13. Théorie de soins, [en ligne] http://www.infirmiers.com/pdf/Theorie\%20de\%20soins\%202.pdf. Consulted 20 February 2015.

14. Brown,L.(2011).Revisiting our roots: Caring in nursing curriculum design. Nurse Education in Practice.360364

15. Collière,M-F.(2001).Soigner : le premier art de la vie. $2^{\text {nd }}$ ed., Paris, Masson,448p.

16. Kutney-Lee,A.D. McHugh,M.Sloane ,D P.CimiottiJ, Flynn L.Felber Neff,D and Aiken,H.(2009).Nursing: A Key To Patient Satisfaction, Health Affairs. DOI 10.1377/ hlthaff.28.4.w669

17. Dingman,S.Williams,M.Fosbinder,D and Warnick,M.(1991).Implementing a Caring Model to Improve Patient Satisfaction The Journal of Nursing Administration.30-37

18. Rafii,F.Hajinezhad,M.Haghani,H.(2007).Nurse caring in Iran and its relationship with patient satisfaction. Australian journal of advanced nursing.Vol.26, Number 2.

19. Green,A.(2004).Caring Behaviors As Perceived by Nurse Practitioners. Journal of the American academy of nurse practitioners.Vol.16, issue 7.

20. Chetoui,A.Papart,J P.(2002).Les urgences dans un hôpital Régional : Profil épidémiologique et étude de la satisfaction des usagers/patients Service régional des urgences de Kébili - Tunisie. Arch Public Health.59-68

21. Essen,L.(1991).The importance of nurse caring behaviors as perceived by Swedish hospital patients and nursing staff, Nurs, Stud. 267-281

22. Dyess,S.Boykin,A.Rigg,C.(2010).Integrating Caring Theory With Nursing Practice and Education, The journal of nursing administration.498-503

23. Brunton,B.Beaman,M.(2000).Nurse Practitioners' Perceptions of Their Caring Behaviors. Journal of the american academy of nurse practitioners.Vol.12, number 11.

24. Murphy,F.Jones,S.Edwards,M.James,J. Mayer A.(2009).The impact of nurse education on the caring behaviours of nursing students. Nurse Education Today. 254-264.

25. Shili,H.B H Hassen,S.Daoud,T.Denguir,H.Ounalli,F.(2018).La profession infirmière en Tunisie. La Tunisie Médicale. Vol $96\left(n^{\circ} 10 / 11\right)$ 